\title{
Clinical Algorithm for Acute Appendicitis in Reducing Negative Appendectomy Rate (NAR)
}

\author{
Dr Aishwarya Avnish ${ }^{1}$, Dr Shireesh Gupta ${ }^{2}$, Dr A. Prakash ${ }^{3}$, Dr Ankit Goyal ${ }^{4}$ \\ 1, 3, 4 Junior Resident, Department of General Surgery, Mahatma Gandhi Medical College and Hospital, Jaipur \\ ${ }^{2}$ Assistant Professor, Department of General Surgery, Mahatma Gandhi Medical College and Hospital, Jaipur \\ Corresponding Author: Dr Shireesh Gupta, 7A Berdiya Colony, Museum Marg, M D road, Jaipur 302004 \\ Email ID: drshireeshgupta@rediffmail.com, 919929789267
}

\begin{abstract}
Appendicitis is the most common cause of acute surgical abdomen with high negative appendectomy rate (NAR),being diagnosed clinically. RIPASA, ALVARADO scoring system along with imaging modalities have been used for accurate diagnosis. In this study an algorithm is established wherein the imaging modalities along with RIPASA scoring system have been used to arrive at the accurate diagnosis thereby reducing NAR. 250 cases of pain in RIF were considered in the study for acute appendicitis. RIPASA and USG in combination were able to diagnose $88 \%$ of the cases with only 2 negative appendectomy, showing high diagnostic accuracy. Cut off value for RIPASA was taken 7
\end{abstract}

Keywords: Acute appendicitis, Scoring system, Negative appendectomy rate

\section{Introduction}

Appendicitis is the most common cause of an acute surgical abdomen with an incidence of $7-8 \%$ in one's whole life ${ }^{[1]}$. Any delay in diagnosing the condition may prove fatal as there are chances of perforation and related complications with high morbidity and mortality ${ }^{[2]}$. Moreover complication rate seems to be higher on either side of age group i.e in children and elderly population.

Acute appendicitis along with its protean manifestations usually mimics almost any acute abdominal illness thereby leading to difficulty in diagnosis. Currently USG, CT and various other modalities are being used to diagnose the condition. Despite all the technological advances, diagnosis of acute appendicitis is primarily based on proper and detailed history and clinical examination. Prompt diagnosis and intervention may reduce the risk of perforation and related complications.

Negative appendectomy rate (NAR) is defined as the rate of surgically removed appendices that are pathologically normal $^{[3,4]}$. NAR varies from $2-11 \%$ and is more in women than men. The ALVARADO score, modified ALVARADO score and the RIPASA score are the scoring systems usually employed in diagnosis of acute appendicitis and help in reducing the negative appendectomy ${ }^{[4,5,6]}$.

Pain migrating from umbilicus to right iliac region is usually considered as the best indicator of acute appendicitis while the absence of pain prior to vomiting almost always rules it out. With the above mentioned diagnostic tools and proper examination concurrently applied together within a single clinical algorithm, it will help reduce the Negative Appendectomy Rate without increasing the rate of complications.

\section{Aims And Objectives}

To evaluate a clinical algorithm in acute appendicitis with the aim to decrease the Negative appendectomy rate by using RIPASA score, USG, CT evaluation and diagnostic laparoscopy without increasing the rate of complications.

\section{Materials and Methods}

This is a prospective study of 250 patients conducted at a tertiary health care centre from September 2015 to March 2017.The study was approved by the Institute Review Board. Written and informed consent was obtained from all patients before their inclusion into the study. Patients presenting to surgical OPD with pain in right iliac fossa were evaluated. Those with a clinical diagnosis of acute appendicitis were included in the study. Exclusion criteria included those patients who were managed conservatively and were discharged without any surgical intervention.

Clinical algorithm was made with the aim to decrease the negative appendectomy rate by using RIPASA score, USG, CT evaluation and diagnostic laparoscopy. 


\section{International Journal of Science and Research (IJSR) \\ ISSN (Online): 2319-7064}

Index Copernicus Value (2015): 78.96 | Impact Factor (2015): 6.391

The algorithmic system:

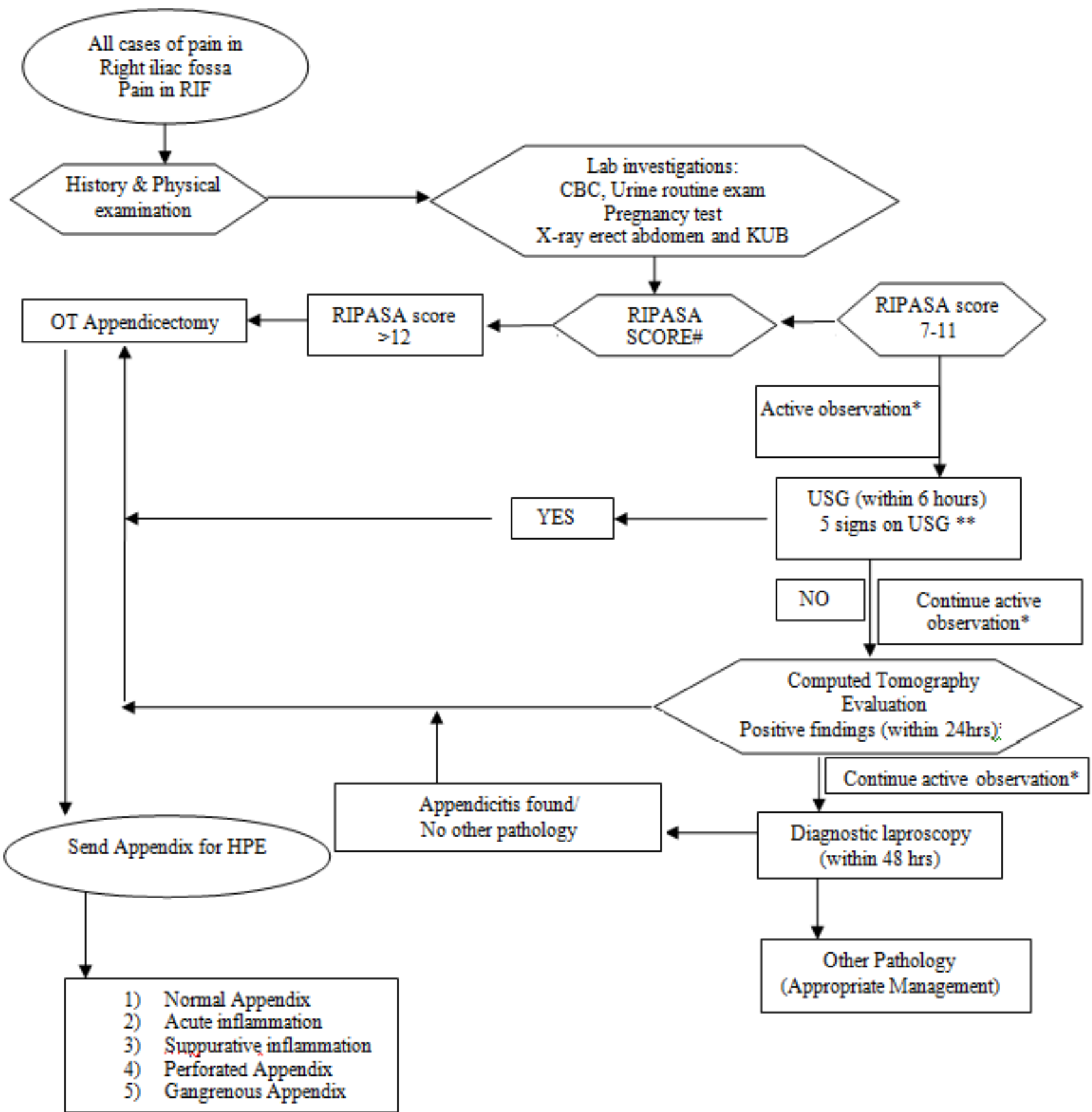

\# Various scoring systems have been developed in the past. RIPASA scoring system is one of the most sensitive and specific system with a specificity and sensitivity above $90 \%$ for a score $>12$. Total score is achieved by adding all the scores for each category together.

Ripasa Score:

\begin{tabular}{|l|rl|l|}
\hline Sr. No. & Criteria & Score \\
\hline 1 & Patients: & \\
& $\bullet \quad$ Female & 0.5 \\
& $\bullet \quad$ Male & 1 \\
& $\bullet \quad<40 y e a r s$ & 1 \\
& $\bullet \quad>40 y e a r s$ & 0.5 \\
\hline 2 & Symptoms: & \\
& $\bullet$ & RIF Pain & 0.5 \\
& $\bullet$ & Pain migrating to RIF & 0.5 \\
& $\bullet$ & Anorexia & 1 \\
& $\bullet$ & Nausea/ Vomiting & 1 \\
\hline
\end{tabular}

\begin{tabular}{|c|c|c|}
\hline & $\begin{array}{ll}\text { - } & \text { Duration }<48 \mathrm{hrs} \\
\text { - } & \text { Duration }>48 \mathrm{hrs}\end{array}$ & $\begin{array}{l}1 \\
0.5\end{array}$ \\
\hline 3 & $\begin{aligned} \text { Signs: } & \\
- & \text { RIF tenderness } \\
\text { - } & \text { Guarding } \\
\text { - } & \text { Rebound tenderness } \\
\text { - } & \text { Rovsing sign } \\
\text { - } & \text { Fever }>37^{\circ} \mathrm{C}<39^{\circ} \mathrm{C}\end{aligned}$ & $\begin{array}{l}1 \\
2 \\
1 \\
2 \\
1\end{array}$ \\
\hline 4 & $\begin{array}{l}\text { Investigations: } \\
\text { - } \quad \text { Raised WBC } \\
\text { - Negative } \\
\text { urine analysis }\end{array}$ & $\begin{array}{l}1 \\
1\end{array}$ \\
\hline
\end{tabular}

Guidelines for management according to total RIPASA score:

- $<5$ = Probability of acute appendicitis is unlikely; observe patient in ward and repeat scoring after 1-2 hrs. If reducing

Volume 6 Issue 7, July 2017 www.ijsr.net

Licensed Under Creative Commons Attribution CC BY 


\section{International Journal of Science and Research (IJSR) \\ ISSN (Online): 2319-7064}

Index Copernicus Value (2015): 78.96 | Impact Factor (2015): 6.391

score, discharge. If increasing score, treat according to score level.

- 5-7.0 = Low probability of acute appendicitis; observe in ward and repeat scoring after 1-2 hrs. Patient may need ultrasound to rule out acute appendicitis. Patients may need admission for observations, discuss with surgeon on-call.

- 7.5-11.0 = Probability of acute appendicitis is high; refer patient to on-call surgeon for admission and repeat score in 1-2 hrs time. If remains high, prepare patient for appendectomy procedure. In female patients, perform abdominal ultrasound investigations to rule out gynaecological causes of RIF pain.

- $>12$ = Definite acute appendicitis; refer to surgeon oncall for admission and appendectomy.

* IV fluids and analgesics

** dilated appendix outer diameter $>6 \mathrm{~mm}$

noncompressible

distinct appendiceal wall layers due to oedema

target appearance (axial section)

appendicolith - an echogenic focus with posterior shadowing

periappendiceal fluid collection fat

echogenic and prominent periappendiceal and pericaecal

surrounding hypervascularity on colour Doppler

***Signs of appendicitis on CT scan include lack of oral contrast (oral dye) in the appendix, direct visualization of appendiceal enlargement (greater than $6 \mathrm{~mm}$ in crosssectional diameter), and appendiceal wall enhancement with IV contrast (IV dye)

All removed appendices were sent for Histopathological examination and were reported as

- Normal appendix

- Acute appendicitis

- Suppurative appendicitis

- Perforated appendicitis

- Gangrenous appendicitis

Perforated and gangrenous appendixes were considered as complications of acute appendicitis.

All the patients were observed post-operatively (on iv antibiotics, iv analgesics and supportive fluids). If there were no complications, sutures were removed and patients discharged on $8^{\text {th }}$ post-operative day.

All the data was collected and statistically analyzed using Chi-square test as applicable using SPSS (version 17) to calculate the overall sensitivities, specificities for the purpose of this study.

\section{Results}

Out of the 250 cases, in 43 cases where the RIPASA score was $\geq 12$, the score was used as the only diagnostic criteria for acute appendicitis and was followed by appendectomy. The RIPASA score was $100 \%$ accurate in these cases. In the remaining 207 patients where the RIPASA score was between 7 and 11, USG was performed within next 6 hours. Out of these, 167 showed signs of acute appendicitis and 11 showed complicated appendicitis, followed by appendectomy and HPE. 2 cases were reported as normal appendix on HPE. The remaining 27 cases with a RIPASA score between 7 and 11 and a negative USG underwent CT scan. 19 cases showed positive sign of acute appendicitis on CT scan with negative appendectomy in 1 case. Rest of 8 cases, where RIPASA score was between 7 and 11 and with negative USG and negative CT scan but with complains of RIF pain and clinical features of acute appendicitis were subjected to diagnostic laproscopy, followed by appendectomy.

\section{Discussion}

Most of the subjects under study were males as compared to females, $63 \%$ and $37 \%$ respectively. In the study by Hasan Erdem et al. (2013), out of the 113 patients with acute appendicitis, 62 were males and $51 \mathrm{females}{ }^{[7]}$.

The most common perioperative finding was acutely inflammed appendix $(81 \%)$ followed by perforated appendix $(8 \%)$, gangrenous appendix $(9 \%)$ and appendicular lump (1.5\%). However, histopathological diagnoses were acute appendicitis (48.8\%), suppurative appendicitis (33.6\%), perforated appendix $(8.0 \%)$, gangrenous appendix $(8.4 \%)$.. Normal histology was seen in $1.2 \%$ cases.

In our study 207 cases who had RIPASA score $7-11.5$ were subjected to USG. The USG findings showed an increased diameter of more than $6 \mathrm{~mm}$ in 163 cases, a target sign in 113 cases, non-compressible appendixes in 96 cases, and wall layer edema in 32 cases. Appendicoliths were seen in 21 patients.

180 cases had positive findings on USG, underwent surgery, and out of these, 167 proved to have acute/suppurative appendicitis on HPE, 11 case of complicated appendicitis and 2 case found be normal. Similar finding were seen in a study conducted by Sachar Sudhir, (2013). The main USG features for diagnosing acute appendicitis were an incompressible appendix with a transverse outer diameter of $>7$ with incompressible periappendicular inflamed fat with or without an appendicolith in there study ${ }^{[8]}$.

The diagnosis of acute appendicitis using RIPASA score with USG and CT scan, confirmed by HPE, was statistically significant. Among 250 cases with positive findings on RIPASA/USG/CT/DL, 247 cases were detected as acute or complicated appendicitis on histopathology.

Giuseppe D'Ippolito,Giselle Guedes Netto de Mello, Jacob Szejnfeld (1998) established the accuracy of unenhanced CT in the preoperative diagnosis of acute appendicitis. Acute appendicitis was confirmed in 19 cases using CT scan ${ }^{[9]}$.

In the present study, NAR came out to be $1.2 \%$. Similar findings were observed in a study by Subedi N, Dangol US, Adhikary MB, Pudasaini S, Baral R (2011) who analyzed clinical presentation of acute appendicitis and its histopathological correlation ${ }^{[10]}$. Out of 345 patients who underwent operative procedure, $98 \%(\mathrm{n}=338)$ were proved to be acute appendicitis. 


\section{International Journal of Science and Research (IJSR) \\ ISSN (Online): 2319-7064}

Index Copernicus Value (2015): 78.96 | Impact Factor (2015): 6.391

\section{Conclusion}

Clinical examination with RIPASA score $\geq 12$ in 43 cases, when used alone, was able to diagnose acute appendicitis with $100 \%$ accuracy, confirmed by HPE. The rate of complicated appendix was as high as $65 \%$ in this group. In cases with RIPASA score 7-11.5, most were acute or suppurative appendicitis, 11 were complicated and a few were normal. Here USG with the classical 5 signs was used as adjunct for diagnosing acute appendicitis.

We were able to diagnose $88.4 \%$ of the cases with the use of RIPASA score and USG with only 2 negative appendectomy. These two modalities together had a high specificity and sensitivity and a high positive predictive value.

In 27 cases who underwent CT scan , 19 were diagnosed as acute appendicitis, out of which 1case turned out to be normal. A cross sectional diameter $>6 \mathrm{~mm}$, was a reliable indicator for acute appendicitis, if we go according to our algorithm.

Diagnostic laparoscopy was used in 8 cases; all of them were confirmed acute appendicitis on HPE. A NAR of $1.2 \%$ was achieved using clinical examination, RIPASA score and all these diagnostic tools with decrease in the acceptable rate of complications. The rate of complications was $16.4 \%$ only.

The cut-off value of RIPASA can be kept as 7 as we found in our study that those with score 7-11.5 had mostly acute/ suppurative appendicitis. By evaluating using this clinical algorithm we were able to reduce the NAR without increasing the rate of complications.

\section{Tables}

Table 1: Association between RIPASA score and HPE in case group

\begin{tabular}{|c|c|c|c|c|c|}
\hline \multirow{2}{*}{$H P E$} & \multicolumn{2}{|c|}{ RIPASA } & Total & Percentage \\
\cline { 2 - 6 } \cline { 3 - 6 } & \begin{tabular}{c}
$\geq 12$ \\
\cline { 4 - 6 }
\end{tabular} & $\begin{array}{c}11.5-7 \\
+v e \\
\text { USG }\end{array}$ & $\begin{array}{c}11.5-7,-v e \\
\text { USG, +ve } \\
\text { CT/+veDL }\end{array}$ & & \\
\hline Acute appendicitis & 9 & 104 & 9 & 122 & 48.8 \\
\hline Suppurative appendicitis & 4 & 63 & 17 & 84 & 33.6 \\
\hline Perforated appendicitis & 14 & 6 & 0 & 20 & 8 \\
\hline Gangrenous appendicitis & 16 & 5 & 0 & 21 & 8.4 \\
\hline Normal appendix & 0 & 2 & 1 & 3 & 1.2 \\
\hline Total & 43 & 180 & 27 & 250 & 100 \\
\hline
\end{tabular}

Table 2: Association between RIPASA with USG/CT/DL findings and HPE in cases group

\begin{tabular}{|c|c|c|c|c|}
\hline & \multicolumn{2}{|c|}{ HPE } & Total & Specificity \\
\cline { 2 - 5 } & $\begin{array}{c}\text { Acute } \\
\text { appendicitis }\end{array}$ & $\begin{array}{c}\text { Normal } \\
\text { Appendix }\end{array}$ & & \\
\hline RIPASA >12 & 43 & 0 & 43 & 100 \\
\hline $\begin{array}{c}\text { RIPASA score } \geq 7 \text { with } \\
\text { positive USG findings }\end{array}$ & 178 & 2 & 180 & 98.8 \\
\hline $\begin{array}{c}\text { RIPASA score >7 with } \\
\text { negative USG findings } \\
\text { but positive CT }\end{array}$ & 18 & 1 & 19 & 94.7 \\
\hline $\begin{array}{c}\text { RIPASA >7, Neg USG, } \\
\text { Neg CT, underwent DL }\end{array}$ & 8 & 0 & 8 & 100 \\
\hline Total & 247 & 3 & 250 & \\
\hline
\end{tabular}

Table 3: Association of Cummulative RIPASA score with USG/CT/DL findings and HPE report

\begin{tabular}{|c|c|c|c|c|}
\hline & \multicolumn{2}{|c|}{ HPE } & \multirow[t]{2}{*}{ Total } & \multirow[t]{2}{*}{ Senstivity } \\
\hline & $\begin{array}{c}\text { Acute } \\
\text { appendicitis }\end{array}$ & $\begin{array}{c}\text { Normal } \\
\text { Appendix }\end{array}$ & & \\
\hline RIPASA $>=12$ & 43 & 0 & 43 & 17.2 \\
\hline $\begin{array}{c}\text { RIPASA score } \geq 7 \\
\text { and/or positive } \\
\text { USG }\end{array}$ & 221 & 2 & 223 & 88.4 \\
\hline $\begin{array}{l}\text { RIPASA score }>7 \\
\text { and/or positive } \\
\text { USG/CT findings }\end{array}$ & 239 & 3 & 242 & 95.6 \\
\hline $\begin{array}{c}\text { RIPASA score }>7 \text {, } \\
\text { and/or positive } \\
\text { USG/CT/DL }\end{array}$ & 247 & 3 & 250 & 98.8 \\
\hline Total & 247 & 3 & 250 & \\
\hline
\end{tabular}

\section{References}

[1] Prystowsky JB, Pugh CM, Nagle AP. Current problems in surgery. Appendicitis Curr Probl Surg. 2005;42(10):688-742

[2] Flum DR, McClure TD, Morris A, Koepsell T. Misdiagnosis of appendicitis and the use of diagnostic imaging. J AmCollSurg 2005;201: 933-939.

[3] Randal Bollinger et al. (2007)Randal Bollinger R, Barbas AS, Bush EL, Lin SS, Parker W. Biofilms in the large bowel suggest an apparent function of the human vermiform appendix. Journal of Theoretical Biology.2007;249:826-831. doi: 10.1016/j.jtbi.2007.08.032

[4] Chong CF, Adi MI, Thien A, et al. Development of theRIPASA score: a new appendicitis scoring system for the diagnosis of acute appendicitis. Singapore Med J 2010; 51:220-25.

[5] Velanovich V, Satava R . Balancing the normal appendectomy rate with the perforated appendicitis rate: implications for quality assurance. Am Surg 1992 ; 58 ( 4 ): 264-69

[6] Wani MM, Yousaf MN, Khan MA, et al. Usefulness of the Alvarado scoring system with respect to age, sex and time of presentation, with regression analysis of individual parameters. Internet J Surg 2007: 11(2)

[7] Marwah Karan, Maheshwari Kumar Mukesh, Krishna Atul, Agarwal Vijay, Kumar Deepak, Jain Atul, Prasad Akshay. Significance of Ripasa Scoring System in Diagnosis of Acute Appendicitis. International Journal of Healthcare Sciences 2015; Vol. 3, Issue 1 4-10)

[8] SacharSudhir, MaheshwariAlok, BalianSubhash, Goyal Sunder, SacharSaurabh, GoyalSnigdha. Comparative study Of ultrasonography (USG) Versus Computed Tomography (CT) In Clinically Suspected Cases Of Acute Appendicitis: Retrospective study Of 100 cases. Journal of Advance Researches in Biological Sciences, 2013, Vol. 5 (2) 191-198

[9] D'Ippolito, Giselle GuedesNetto de Mello, Jacob Szejnfeld. The value of unenhanced CT in the diagnosis of acute appendicitis. Rev Paul Med 1998;116(6):183845

[10] Subedi N, Dangol US, Adhikary MB, Pudasaini S, Baral R. Acute appendicitis: a 2year review of clinical presentation and histopathology. Journal of Pathology of Nepal (2011); Vol. :104 -107 